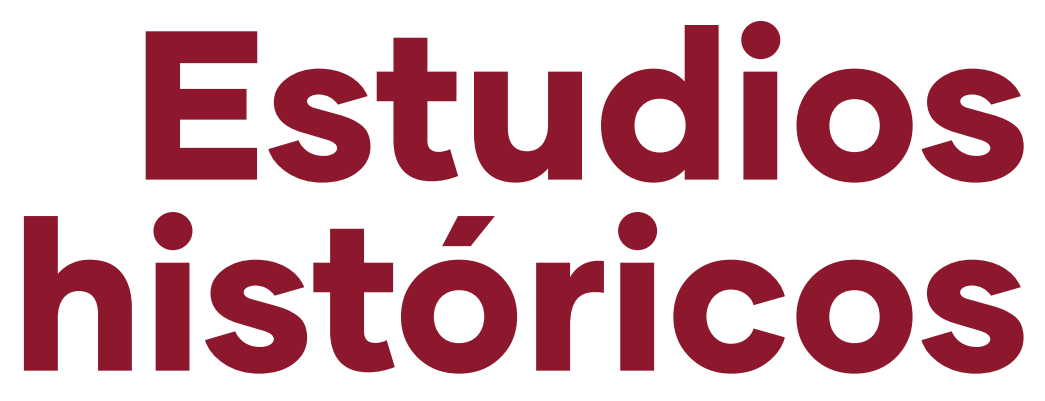

\title{
La historia local, la historia regional y la microhistoria como experiencia y posibilidad para la historia pública
}

Local history, regional history and microhistory as experience and possibility for public history

Recibido: 31 de diciembre de 2020

Aceptado: 17 de noviembre de 2021

DOI: $10.22517 / 25392662.24623$

pp. 1-18

Álvaro Acevedo Tarazona*

tarazona20@gmail.com

https://orcid.org/0000-0002-3563-9213
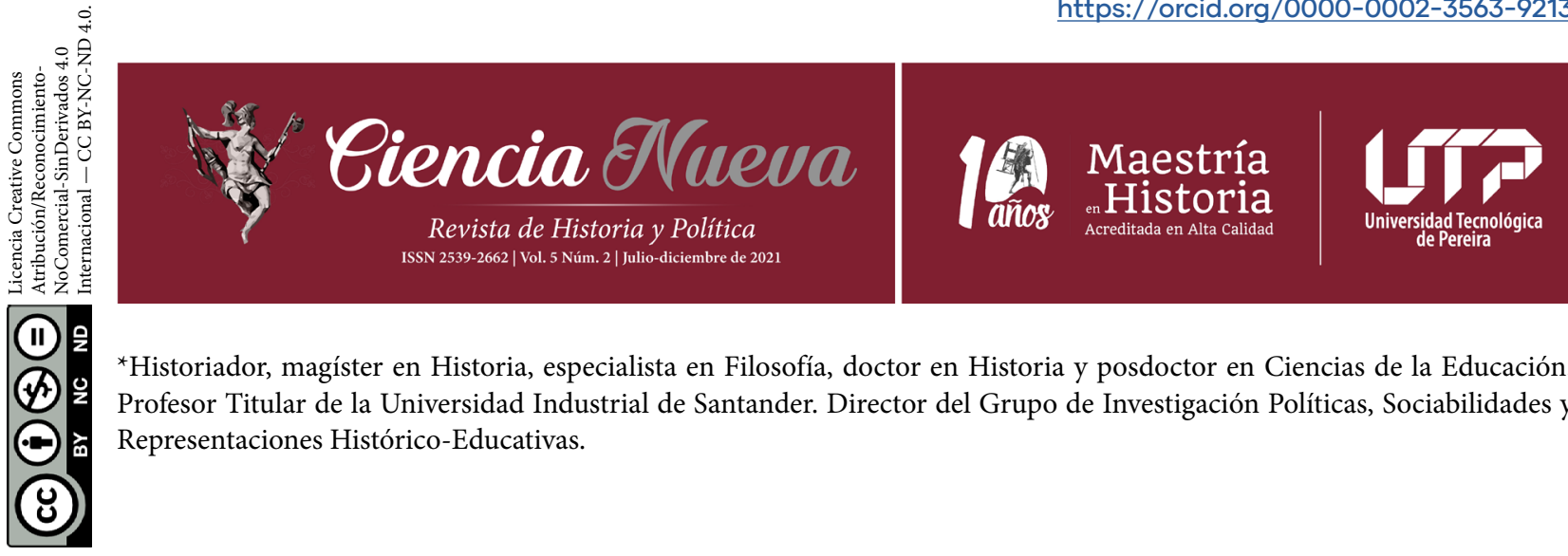

${ }^{*}$ Historiador, magíster en Historia, especialista en Filosofía, doctor en Historia y posdoctor en Ciencias de la Educación. Profesor Titular de la Universidad Industrial de Santander. Director del Grupo de Investigación Políticas, Sociabilidades y Representaciones Histórico-Educativas.

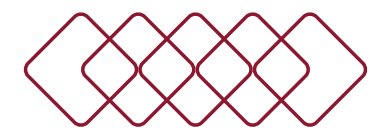


Resumen

Este artículo contribuye al conocimiento de la historia pública a partir del quehacer de la historia local y de la historia regional. De la misma manera, reconoce las limitaciones, alcances y posibilidades de articulación y análisis de la historia local y regional con la historia general. Asimismo, presenta reflexiones teóricas y metodológicas que establecen diferencias y complementariedades, entre estas dos alternativas de hacer historia, que se orientan al estudio de unidades de análisis de lo singular colectivo. También se incluye un apartado sobre la microhistoria, sus posibilidades de articulación con la historia general, sus relaciones y diferencias con la historia local y regional y su quehacer como historia pública.

Palabras clave: historia general, historia local, historia pública, historia regional, microhistoria.

\section{Abstract}

This article contributes to the knowledge of public history from the work of local history and regional history. In the same way, it recognizes the limitations, scope and possibilities of articulation and analysis of local and regional history with general history. Likewise, it presents theoretical and methodological reflections that establish differences and complementarities between these two alternatives of making history that are oriented to the study of units of analysis of the collective singularity. It also includes a section on microhistory, its possibilities of articulation with general history, its relationships and differences with local and regional history, and its role as public history.

Keywords: General history, Local history, Public history, Regional history, Microhistory.

\section{Introducción}

La historia además de constituirse en una disciplina propia de las ciencias sociales es una necesidad de las sociedades y de los individuos para asumir el devenir temporal y representativo en el que se está inmerso. El tiempo histórico está sujeto a un devenir y este a su vez a una espacialidad. Las derivaciones en los sistemas de pensamiento moderno y occidental más recientes han tratado de advertir que nuestro acontecer es minúsculo en comparación con el desplazamiento físico del universo. La historia se enmarca en la explicación racional que el ser humano ha construido para comprender el devenir de sus acontecimientos. Este recorrido entre lo que ha sido, es y será ${ }^{1}$ configura las representaciones, los temores y, en general, la noción existencial en la sociedad.

Para alcanzar el objetivo propuesto de reconocer la historia pública sobre la base de la experiencia aportada por la historia local y la historia regional se ha seguido una metodología de enfoque hermenéutico desde la cual se busca su relación a partir de la reflexión de las lecturas de apoyo y resultados investigativos. Este artículo se divide en tres apartados, el primero

1 Arthur Eddington, Space, time and gravitation (Cambridge: Cambridge University Press, 1920). 
acerca al lector a conocer la relación entre historia local e historia pública, un segundo que permite conocer la labor de la historia regional y una tercera parte que muestra un posible consenso entre historia local, historia regional y microhistoria. Estos apartados se construyen a partir de los trabajos de historiadores expertos en la concepción teórica de la historia, sus alcances y problemas.

\section{Historia local, historia pública}

Si la historia local explica o comprende las relaciones de un singular colectivo, esto es, el devenir particular de un grupo humano con una relativa interdependencia, la intención de este propósito no es otro que hacer historia pública, en tanto se permite que emerja un grupo humano como un propio público dispuesto a reconocerse distinto en el devenir de la historia general. Además, la historia local permite que un grupo humano se deslinde o se separe de los encasillamientos de los relatos hegemónicos nacionales y universales, sin que esto implique negar la historia general de la cual un grupo humano también hace parte.

La historia local en su análisis o comprensión de un colectivo tampoco excluye la diversidad, ya sea para reconocer la diferencia entre ellos mismos o entre otros diferentes. De manera que la historia local es un desocultamiento, un dejar ver a los grupos humanos, y al realizarlo hace públicas las acciones de un singular colectivo.

La historia local es entonces historia pública de un singular colectivo no homogeneizado ni masificado; también es la posibilidad de ver la distinción, la divergencia de un grupo humano. Por tanto, «la historia pública es el acercamiento de la disciplina a distintos públicos o sectores de la población, desde contextos propios o situados» ${ }^{2}$, es decir, «es un campo con la capacidad de adoptar diferentes formas que inclusive varían mucho dependiendo del país desde el cual se desarrollan ${ }^{3}$. De esta manera, cualquier sitio físico (plaza, parque, aula) o espacio virtual (plataformas digitales, redes sociales, blogs) se constituye en una forma de transmisión de la historia, desde cualquier sitio, en cualquier momento y a cualquier individuo perteneciente a una sociedad. La historia local, en calidad de historia pública, reconoce que cada grupo humano en su singularidad o particularidad no es igual a otro. La historia local, en calidad de historia pública, da posibilidades de emergencia al grupo humano en su devenir (estar en el mundo) $)^{4}$. Pero lo público no es el «ser» de la masa que le quita al devenir sus posibilidades de ser ${ }^{5}$; es todo lo contrario, la posibilidad de estar en el mundo en la diferencia, en la distinción, en la propiedad de ser.

Este emerger de lo público en la historia local adquiere sentido de apropiación en el rigor del tratamiento de las fuentes de investigación y en la organización interpretativa de los

2 Daniela Torres Ayala, «Historia pública. Una apuesta para pensar y repensar el quehacer histórico», Revista Historia y Sociedad 38 (2020): 231.

3 Torres Ayala, «Historia pública. Una apuesta para pensar y repensar el quehacer histórico», 231.

4 Martin Heidegger, Ser y tiempo (Santiago de Chile: Editorial Universitaria, 1998), 287-289.

5 Byung-Chul Han, El aroma del tiempo: un ensayo filosófico sobre el arte de demorarse (Barcelona: Herder, 2015$), 17$.

\section{Estudios históricos}


hechos acaecidos por un grupo humano. La peculiaridad de la historia local radica en el tratamiento que se da al acontecer de un grupo humano mediante las fuentes y los procedimientos metodológicos de la heurística y la crítica, los cuales son dispuestos por el historiador para interpretar los hechos individuales en su acontecer fáctico, y así descubrir el entramado que los vincula colectivamente, y así fundarse en localidad.

Por consiguiente, la historia local alcanza una mayor cercanía frente al pasado como fue acaecido al tomar distancia de las historias generales o temáticas que diluyen los detalles particulares de las comunidades. La historia local, ya se ha dicho, permite diferenciar un grupo humano sin negar su diversidad, pero, ante todo, no es una historia unidimensional que olvida la variedad de aspectos que la conforman. En este sentido, la historia local se diferencia de la microhistoria en que es la historia de una comunidad con una temporalidad más amplia y con un propósito de interpretar la historia total de un grupo humano, es decir, con la pretensión de mirar todos los aspectos en el devenir de un singular colectivo y no solo una parte o tematización del este.

De ser así, se estaría de acuerdo con Francisco Uriel Zuluaga, quien define la historia local como aquella que recupera la vida cotidiana y presenta a los individuos estableciendo relaciones con los otros para descubrir acciones, actividades y conductas propias de las comunidades estudiadas en el ejercicio de una cotidianidad activa ${ }^{6}$. La historia local, además, es el estudio de un punto determinado y ubicado en el espacio: la localidad. Pero siempre será una localidad intervenida por seres humanos. La elección de su estudio, en la mayoría de los casos, se da a partir de criterios personales, causales, azarosos o anecdóticos ${ }^{7}$. Lo cual no quiere decir que la historia local sea menos o que esté en un nivel inferior a la historia que se hace con pretensiones científicas o analíticas en sentido estricto. Lo local es aquello entonces que da sentido de pertenencia, lo que da sitio $^{8}$, aquello propio y público que nos pone en un determinado lugar alrededor del cual se manifiestan tareas, reglas, patrones de la sociedad, de los individuos que se transforman en colectivo y a partir del cual se generan historias para la historia (historiografía).

A la escueta pregunta: ¿qué es la historia local?, la respuesta incluso se puede situar en la misma definición de local como condición de sitio o lugar donde se localiza algo o alguien. También como el lugar para localizar a alguien (comunidad) ubicado en dicho lugar; el sitio para que una comunidad se localice, se distinga y se relacione públicamente con otras comunidades. Local (o localidad) es lo propio y de lo que se es propio. Por tanto, lo local sitúa al ser humano en un angustioso gestarse histórico social, en la urgencia y el alcance de estar ocupado y solícito en el mundo con sus manifiestas prácticas económicas, políticas

6 Francisco Uriel Zuluaga Ramírez, «Historia local y hermenéutica», Historelo. Revista de Historia Regional y Local 2 , n. ${ }^{\circ} 3$ (2010): 143-155.

7 Carlos Antonio Aguirre Rojas, «La historia regional en la perspectiva de la corriente francesa de los Annales», Revista Historia y Memoria 11 (2015): 274-275.

8 Francisco Uriel Zuluaga Ramírez, «Otro paso en la reflexión sobre historia local», Historelo. Revista de Historia Regional y Local 1, n. ${ }^{\circ} 2$ (2009): 169-181.

9 Francisco Uriel Zuluaga Ramírez, «Oteando el horizonte de la historia local», en Historia Local. Experiencias, métodos y enfoques, comp. por Renzo Ramírez (Medellín: La Carreta, 2005), 113-134. 
y culturales que dan identidad y lugar frente a otros (y otras comunidades). Esta identidad como identificación pública frente a otros configura un espacio, ejerce una territorialidad, se organiza en sociedad y produce concepciones sobre el mundo. En otras palabras, lo local se hace y produce cultura.

El concepto de local o localidad en el que convergen palabras, como territorialidad, sociedad, forma de vida, cultura, crea entonces un nosotros, un colectivo de historias individuales. Precisamente, un nosotros en el que se construyen mundos que dan cuenta del colectivo singular del que se proviene; una distinción o diferenciación pública que no se puede simplemente generalizar.

La historia local también se inscribe hoy en los debates historiográficos que proponen investigaciones con énfasis en problemas. La apuesta es clara por impulsar la construcción teórica y metodológica de una historia local y regional, interdisciplinaria, en diálogo con la sociología ${ }^{10}$.

En esta perspectiva interdisciplinaria, la historia local no es distinta a lo expresado en tanto se encarga del estudio de las acciones de los seres humanos en referencia a una comunidad específica en un lugar. No obstante, es necesario recurrir a las múltiples posibilidades que ofrecen la experiencia metodológica de la sociología y la antropología, las cuales se consideran un modo de hacer historia práctica en y para la sociedad actual. De manera que también es posible hacer una historia contemporánea local con base en fundamentos metodológicos prácticos que dialoguen con lo global o lo más general ${ }^{11}$. En este sentido, por su carácter público, la historia local no es una historia anónima pero tampoco es una colección de biografías (historia parroquial), sino que presta atención por igual al individuo y a la multitud ${ }^{12}$.

Lo que se busca es que los estudios de las localidades y las unidades que tienen su particularidad, incluyendo la historia regional, no se vuelvan una excusa para olvidar los conectores con lo global, pues la historia local y la historia regional no tradicional sentaron sus bases en la historiografía nacional a través de textos realizados por historiadores académicos.

Si bien es posible que la historia local puede fundamentarse en el seguimiento de criterios personales que conducen a la delimitación del objeto de estudio, tal proceder como punto de partida no la invalida. Esto además implica reconocer que la historia local se vale de aquello que se le refutó con severidad a la historia académica que no se guiaba por criterios estrictamente científicos.

Si la historia local es un acercamiento a las especificidades permite entonces explicar

10 Armando Martínez Garnica, «La historia local desde la perspectiva de la sociología de los regímenes», en Historia Local. Experiencias, métodos y enfoques, comp. por Renzo Ramírez (Medellín: La Carreta, 2005, 29-60).

11 Renzo Ramírez Bacca y Álvaro Acevedo Tarazona, Identidades, localidades y regiones. Hacia una mirada micro e interdisciplinaria (Medellín: La Carreta Histórica, 2007).

12 Alexander Betancourt, «El problema de la historia tradicional. A propósito de la reedición de dos obras clásicas de la historia local», en Identidades, localidades y regiones. Hacia una mirada micro e interdisciplinaria, comp. por Renzo Ramírez Bacca y Álvaro Acevedo Tarazona (Medellín: La Carreta, 2007), 51.

\section{Estudios históricos}


de una manera más cercana el acontecer de un grupo humano ${ }^{13}$. Este acercamiento son los sucesos que le imprimen un carácter histórico a un grupo humano y hacen parte de su pequeña historia, base que compone sustancialmente la historia general; es decir, la historia de una localidad es un elemento sustancial de lo que discurre en lo regional, lo que a su vez sustenta la historia nacional.

El acercamiento que hace la historia local a las especificidades requiere ir a las fuentes de investigación, a la recopilación de muchas vivencias para comprender las conductas y la cultura, pero, ante todo, requiere hacerse con mucha simpatía con el lugar y grupo humano que se está estudiando ${ }^{14}$. La historia local recupera la vida cotidiana y sitúa a los individuos en un acontecer diacrónico activo y público con base en acciones y conductas propias de un grupo humano, para ser presentadas en una interpretación que establece relaciones entre los individuos ${ }^{15}$.

Es decir, que una característica fundamental de esta forma de analizar las relaciones humanas es el grupo humano, entendido como proyectos singulares individuales con una relativa interdependencia. Cabe señalar que la singularidad de un colectivo no excluye la diversidad, bien para reconocerse entre otros diferentes o para reconocer la diferencia entre varios nosotros. Por tanto, la certeza y credibilidad de la historia local descansa en el rigor del tratamiento de las fuentes y la organización de los hechos, como se señaló anteriormente. Y es precisamente en el análisis de las fuentes que se halla la peculiaridad de la historia local, pues ella, a través de la heurística y de la crítica, se pone a disposición del historiador para que establezca los hechos individuales y descubra el entramado que los vincula colectivamente y como tal fundarse en la localidad. Por consiguiente, la historia local alcanza una mayor cercanía frente al pasado al tomar cierta distancia de las historias generales o temáticas que diluyen los detalles particulares de las comunidades y que a su vez, les permite diferenciarse sin negar la diversidad, al convertirse en historias unidimensionales.

En este debate conceptual, argumenta Koselleck que la historia local es «la determinación del sentido literal e ideal de las fuentes»; por consiguiente, «la comprensión de ideas y conductas debe hacerse con muchas vivencias, larga reflexión, cultura variada y con el máximo de simpatía ${ }^{16}$. Hoy se reconoce la conveniencia de una redefinición del enfoque desde el debate entre los historiadores para plantear una alternativa a los enfoques productores de historias con énfasis en temas o problemas como la historia cultural o que hacen énfasis en la cultura y las mentalidades como en el caso de la microhistoria.

Ahora bien, si la historia local siempre es la historia de un grupo humano en un punto determinado ubicado en el espacio, y su interés no parte propiamente de criterios estrictamente científicos o académicos, ¿acaso hacer historia local es lo mismo que hacer historia

13 Juan Antonio Lacomba, «La historia local y su importancia», en Actas I Congreso de Historia de Linares, coord. por Vicente Leis Sánchez, Lorenzo Martínez Aguilar y Luis Rabaneda Sánchez (Linares: Centro de Estudios Linarenses, 2008), 470.

14 Zuluaga Ramírez, «Historia local y hermenéutica», 146.

15 Zuluaga Ramírez, «Historia local y hermenéutica», 148.

16 Zuluaga Ramírez, «Historia local y hermenéutica», 146. 
regional? Hasta aquí se ha argumentado que la historia local es ante todo historia pública de un colectivo dispuesto a reconocerse distinto en el devenir de la historia general, y sin que esto implique que no haga parte de una historia general e incluso de una historia regional.

Para responder al interrogante si hacer historia local es hacer lo mismo que hacer historia regional, de entrada, se intentará sustentar que no es lo mismo. Y si no es lo mismo, ¿cuál es la diferencia entre hacer historia local y hacer historia regional?, ¿qué se entiende por una región? y, más específicamente, ¿qué se entiende por una región histórica, y cómo se delimita? ¿Hacer historia regional es hacer historia pública?

\section{Hacer historia regional}

Hacer historia regional es abordar problemáticamente un lugar transformado por gentes que lo habitan y se desenvuelven en este. De manera que la elección para hacer historia regional no es necesariamente, en principio, una relación de simpatía con los seres humanos que habitan y transforman un lugar. Hacer historia regional es hacer una representación analítica con base en problemas de índole general para ser resueltos a partir de las fuentes de investigación y, particularmente, teniendo en cuenta el desenvolvimiento histórico de un lugar habitado y transformado con un origen y posteriores desarrollos, auges, estancamientos, decadencias e incluso desaparición.

La historia regional propone entonces hacer una representación analítica de un lugar habitado y transformado históricamente, donde convergen fundamentos geográficos para su comprensión y relaciones con temas y problemas de la historia general ${ }^{17}$. De manera que hacer historia regional, siguiendo a Carlos Antonio Aguirre, es hacer la historia de una individualidad geohistórica ${ }^{18}$, lo cual también implica considerar que una región histórica, cambiante e incluso efímera, es distinta a una región económica, política o cultural ${ }^{19}$.

La historia regional para ser científica debe entrar en constante diálogo con la historia general y no solo quedarse en la descripción de una región o localidad. Por tanto, no puede elegirse como objeto de estudio cualquier localidad, sino solo aquella que, desde rigurosos criterios históricos, presenta una clara relevancia para el historiador, en la medida en que es realmente significativa o reveladora de aquellos procesos políticos, sociales y culturales específicos que el historiador está analizando en particular.

En sus comienzos, la importancia de la historia regional radicó en su respuesta a la historia oficial y su discurso nacional homogeneizante, el cual de alguna manera no prestaba atención a las particularidades existentes en una nación. Pero a pesar de esta buena intención, en muchos casos la historia regional quedaba reducida a la mera descripción, perdiéndose en la especificidad. De ahí que se hiciera un llamado a prestar atención a los procesos generales

17 Aguirre Rojas, «La historia regional en la perspectiva de la corriente francesa de los Annales», 276.

18 Aguirre Rojas, «La historia regional en la perspectiva de la corriente francesa de los Annales», 286, $296-297$.

19 Aguirre Rojas, «La historia regional en la perspectiva de la corriente francesa de los Annales», 276, 288.

\section{Estudios históricos}


históricos que inciden en los hechos particulares de una región histórica. La historia regional puede tener un carácter analítico siempre y cuando entre en constante diálogo con lo universal y no reduzca su análisis a la importante pero estrecha particularidad.

Si bien la historia regional se presenta como una alternativa a los relatos históricos nacionales y hegemónicos, sus interpretaciones no deben necesariamente deslindarse de la perspectiva nacional y general. Pues la historia que crea sentido analítico es la historia que al mismo tiempo reconstruye lo particular y lo general, esto es, las dimensiones únicas e irrepetibles de los procesos históricos al mismo tiempo que elementos y características generales y universales. Este propósito también implica recurrir analíticamente a la relación dialéctica entre lo particular y lo general, observando las diversas conexiones existentes entre los aspectos generales que subyacen a los procesos históricos, así como los elementos particulares que los caracterizan y los hacen irrepetibles.

Para constituirse en historiador regional se requiere, preferiblemente, convivir en su territorio, su cultura; conocer las actividades y ocupaciones de las gentes de la región que se propone delimitar, y a partir del análisis de los detalles tratar de ir a lo general de la explicación. La región es «un espacio de inserción de una comunidad cultural» ${ }^{20}$. Los retos y perspectivas de la historia regional son potenciar su nivel de incidencia en los procesos nacionales, así como exponer procesos particulares que se distancien de proyectos políticos nacionales. Y en este sentido, la historia nacional es pública porque no todos los pueblos o grupos humanos en una frontera nacional ocupan la misma jerarquía ni el mismo poder.

Hacer historia regional implica flexibilizar modelos, sean políticos, económicos o de estructuras mentales, y replantear metodologías y técnicas de abordajes. Ello no quiere decir que se abandonen representaciones generales, sino que se complejicen y que el péndulo de la balanza también se incline a la singularidad ${ }^{21}$.

El reto para hacer historia regional está en integrar al análisis la historia general y la historia local, al mismo tiempo que incorporar tematizaciones económicas, sociales, políticas, culturales e incluso territoriales, según el interés del investigador y lo que este finalmente se propone dimensionar. El análisis de una región tampoco puede desconocer los fundamentos geográficos de la acción humana, en tanto que distintas configuraciones posibles conducen a diversas respuestas. Pero, ante todo, la historia regional debe tener la posibilidad de plantearle preguntas y respuestas a la historia general ${ }^{22}$.

En Colombia la historia regional se convirtió desde los años ochenta del siglo pasado en una alternativa metodológica dentro de la joven historiografía profesional colombiana ${ }^{23}$. Desde ese momento y en ciertos casos posibilitó elaborar representaciones históricas carac-

20 Renzo Ramírez Bacca, «Tendencias de la historia regional en Colombia. Problemas y perspectivas recientes», Historelo. Revista de Historia Regional y Local 3, n. ${ }^{\circ} 5$ (2011): 147-168.

21 María Rosa Carbonari, «De cómo explicar la región sin perderse en el intento. Repasando y repensando la historia regional», Historia Unísonos 13, n. ${ }^{\circ} 1$ (2009): 32.

22 Aguirre Rojas, «La historia regional en la perspectiva de la corriente francesa de los Annales», 295.

23 Álvaro Acevedo Tarazona, «La historia regional: un campo abierto de problemas», Revista de Ciencias Humanas UTP 11, n. ${ }^{\circ} 4$ (2005): 99-108. 
terizadas por sus densas descripciones y ciertas displicencias teóricas; no obstante, lograron visibilizar aspectos históricos regionales tradicionalmente opacados, además de separarse de representaciones histórico-patrióticas-nacionales. Los propósitos descriptivos de esta historia regional eran, de igual manera, alejarse de los contenidos ideológicos.

Ahora bien, si la historia regional precisa ser tan completa como lo permitan las fuentes $^{24}$ (por lo cual se nutre de fuentes orales, escritas, de la tradición oral, fuentes monumentales, de utensilios arqueológicos, entre otros más), es claro que esta surgió como respuesta a las historias oficialistas. Sin embargo, desde su profusión también fue considerada como un género menor al perder su fuerza explicativa y dirigirse a la descripción e incluso a la simple colección de datos sobre un lugar habitado y transformado.

La historia regional científica, si se permite la expresión, surgió de la primera tendencia de la denominada Escuela de Annales ${ }^{25}$. Su propósito interdisciplinario, en diálogo con la geografía humana, quiso reaccionar al determinismo geográfico e incluso plantear alcances explicativos totales. De hecho, hay quienes consideran que la historia regional debe ser un concepto operativo, sin perder la riqueza de su especificidad, para completar los niveles explicativos de la disciplina ${ }^{26}$.

Lilian Vizcaíno González sostiene que la historia regional es mucho más que un método o forma de abordar el estudio de la historia, ya que esta cuenta con un cuerpo teórico o conjunto articulado de conceptos que se integran y que tienen como objeto de estudio propio la región como unidad de análisis ${ }^{27}$. De manera que el estudio de una región determinada no solo se reduce al análisis de su estructura interna y a las relaciones intrarregionales que la caracterizan, sino que también precisa tener en cuenta los vínculos que establece con el sistema en general en la cual está inserta.

También se argumenta que la historia regional es aquella que responde a un atributo histórico que se relaciona generalmente con la homogenización del paisaje, con alguna actividad económica que tiene la suficiente fuerza para definir un territorio, con imprecisas categorías culturales o con regímenes políticos inexistentes ${ }^{28}$. Pero autores como Manuel Miño Grijalva llegan a poner en duda la misma existencia de la historia regional, y a tal punto que caracteriza a esta como un fantasma cuya identificación varía según el profesional que se acerque a ella estableciendo delimitaciones geográficas o jurídicas. En últimas, lo que Miño Grijalva sostiene es que la región no precisa de conceptos sobre los cuales haya un consenso para su delimitación. En consecuencia, tampoco cuenta con un cuerpo metodológico o analítico específico ${ }^{29}$. «Región», además, es un término proveniente del lenguaje propio de oficinas de

24 Manuel Miño Grijalva, «¿Existe la historia regional?», Historia Mexicana LI, n. ${ }^{\circ}$ (2002): 870.

25 Aguirre Rojas, «La historia regional en la perspectiva de la corriente francesa de los Annales», 273-297.

26 Orietta Favaro y María Carolina Scuri, Sujetos sociales y políticos. Historia reciente de la Norpatagonia Argentina (Buenos Aires: Clacso, 2005).

27 Lilian Vizcaíno González, «La historia regional. Mitos y realidades», Tzintzun: Revista de Estudios Históricos 27 (1998): 117.

28 Sebastián Martínez Botero, «La necesaria existencia de la historia regional o la tarea por construir la región», Gestión y Región 14 (2012): 12.

29 Manuel Miño Grijalva, «¿Existe la historia regional?», 867-868.

\section{Estudios históricos}


planeación y políticas públicas de entes departamentales y nacionales, cuyo propósito ha sido la elaboración de una herramienta útil para la gestión administrativa del cálculo demográfico, productivo y ambiental ${ }^{30}$. En el mismo orden de ideas de Miño Grijalva, Armando Martínez sostiene que «el término región parece ser un receptáculo semántico vacío, susceptible de ser llenado con cualquier contenido, de tal manera que en cada una de las disciplinas científicas puede tener disímil connotación $»^{31}$. Para terciar en la discusión, el propio Armando Martínez Garnica reconsidera que en Colombia las historias regionales están determinadas por las posibilidades que ofrecen los archivos locales y regionales, por lo que esta nueva forma de hacer historia es ni más ni menos que la historia de las jurisdicciones político-administrativas o la historia de los poblamientos humanos ${ }^{32}$.

Hoy, además, la historia regional ya no es la gran tendencia historiográfica en Colombia como lo fue desde los años noventa del siglo pasado. El protagonismo lo tiene ahora la historia cultural, la cual es un fenómeno historiográfico evidente en los últimos años ${ }^{33}$. Pero lo cierto es que se sigue haciendo historia regional en Colombia de cara a la configuración de una nación con marcadas diferencias regionales y subregionales. Una distinción sobre la cual hay un consenso en la comunidad de investigadores sociales del país. Por ello se hizo y se seguirá haciendo historia regional en Colombia. Una historia que demanda ser historia pública para entender aún más la complementariedad entre historia regional e historia general, y más aún para reconocer la tensión entre la historia regional y los relatos nacionales homogeneizantes. Por último, también para reconocer que la historia nacional no es la suma de historias regionales.

Sin embargo, la historia regional debe entenderse como procesos históricos que de cierta manera se deben desligar del relato nacional, pues la historiografía intenta abordar sus respectivas investigaciones con relación a dichos fines. La historiografía regional se presenta como alternativa ante los relatos históricos nacionales y hegemónicos del discurso nacionalista. Sin embargo, la historia regional debe existir en función casi exclusiva de la historia nacional, es decir, que los relatos de este campo disciplinar deben necesariamente enlazarse a una narrativa construida a partir de la perspectiva nacional.

En conclusión, la historia regional se entiende como la reconstrucción de manera científica de la evolución histórica de una región determinada. Su diferencia con la historia local radica en que esta última recoge motivaciones propias de quien la hace, mientras que la historia regional tiene mayor amplitud no solo en el aspecto geográfico sino también en el estudio que se hace de los individuos, de sus dinámicas y de sus intervenciones en el territorio donde estos se agrupan, como se analizará a continuación.

30 Martínez Botero, «La necesaria existencia de la historia regional o la tarea por construir la región», 12.

31 Armando Martínez Garnica, «Los conceptos de la historia regional santandereana», en Fronteras, regiones y ciudades en la historia de Colombia, coord. Amado Antonio Guerrero Rincón (Bucaramanga: Universidad Industrial de Santander, 1993), 175.

32 Diana González Rey, «Entrevista a Armando Martínez Garnica», Historia 2.0 IV, n. ${ }^{\circ} 8$ (2014): 144-145.

33 Phillippe Poirrier, ed. La historia cultural: ¿Un giro historiográfico mundial? (Valencia: Universitat de Valencia, 2012), $10-14$. 


\section{Historia local, historia regional y microhistoria, complementariedad en la diferencia}

Como se mencionó anteriormente el debate del quehacer de la historia regional sigue vigente en el campo historiográfico, aunque algunos historiadores la han considerado poco factible o viable. Entre esos autores está Carlos Antonio Aguirre, quien hace una crítica a las perspectivas posmodernas, que, tratando de definir el concepto de región desde diferentes disciplinas, terminan por desgastar y enredar el término, al punto de perder el sentido y la raíz de lo que es. Como una medida de control, Aguirre propone asumir un trato más riguroso en lo que se define y se precisa como región o historia regional, pues considera que los historiadores cometen un grave error al comparar y equiparar la historia local y la historia regional.

La historia local se define como la historia de un lugar específico. De acuerdo con Marc Bloch, esta es elegida a partir de criterios personales, casuales, azarosos, criterios extracientíficos o extrahistóricos, que se plantea el historiador. Estos motivos no deben ser tomados a la ligera, pues cuando se habla del verdadero objeto de estudio de la historia local, el investigador no puede elegir esta localidad por azar o casualidad, en realidad, de acuerdo con el discernimiento del historiador, debe descubrir lo trascendente o relevante de la localidad para articularle con los procesos específicos de su estudio histórico o análisis en particular.

La región siempre se remite a la dialéctica de ciertos elementos con los fundamentos geográficos; es decir, la región es una realidad cambiante y efímera, por lo que el historiador debe estar atento a lo particular de esa región, pues la región histórica no es solo un movimiento individual histórico, sino que tiene que ver con las dimensiones geohistóricas. Porque las sociedades no se mueven solas, es la misma geografía de la región la que interviene como factor central para el desarrollo de esas sociedades.

Ahora bien, no es lo mismo la historia local, la microhistoria o la historia regional, y con frecuencia, el caer en estas nociones que parecen comunes es lo que hace demeritar el compromiso y la seriedad de cada una de ellas.

Si bien la historia local, la microhistoria y la historia regional poseen semejanzas, cada una tiene un enfoque distinto, o más bien, cada una parte de una premisa diferente. Así pues, la historia regional se encarga de esclarecer que todo suceso o proceso tiene una temporalidad y un espacio, que son posibles de estudiar desde la perspectiva de regiones históricas, esto es, desde la historia de seres humanos que se desenvuelven en un territorio. En consecuencia, esta historia regional está vinculada a la geografía, permitiendo en cierta medida arrojar como resultado un estudio histórico relacionado con una historia más general. Por consiguiente, la historia regional busca preguntarse por el acontecer de individuos desenvolviéndose en territorios particulares. Es decir, la historia regional se aproxima a la comprensión de seres humanos que dan origen a formaciones sociales, productivas e institucionales-administrativas interconectadas con estos mismos procesos a mayor escala ${ }^{34}$. De acuerdo con Xenia von Tippelskirch, la historia de la vida cotidiana se centra «en realidades locales y regionales»

34 Álvaro Acevedo Tarazona, «Avatares y tránsitos de la historia regional a la historia cultural: incertidumbres, extravíos y reencuentros», en Los historiadores colombianos y su oficio: reflexiones desde el taller de la historia, edit. Helwar Figueroa, José David Cortés Guerrero y Jorge Enrique Salcedo Martínez (Bogotá: Pontificia Universidad Javeriana, 2017), $226-247$.

\section{Estudios históricos}


y se deriva «de la microhistoria desarrollada por Giovanni Levi y Carlo Ginzburg» ${ }^{35}$. Precisamente son esas realidades regionales las que permiten comprender el desarrollo de los seres humanos en una sociedad desde la política o la economía, por poner solo un ejemplo.

Retomando el concepto de historia local, esta se caracteriza por ser la historia de un punto determinado y ubicado en el espacio, es decir, de una porción geográfica más pequeña que la región y que tiende a funcionar como un sistema semicerrado, en el que acontecen situaciones que, si bien están ligadas con procesos ocurridos en otras partes, no dependen necesariamente de ellos.

Por último, está la microhistoria, la cual ha sido entendida como una forma de hacer historia desde la mirada de un individuo y de acciones y actitudes cotidianas específicas. Además, parte del estudio de localidades como pueblos o aldeas. Es decir, a partir de este tipo de estudio se realiza un acercamiento a una población desde un suceso en concreto, lo cual, según plantea Manuel Miño permitiría adentrarse a la región ${ }^{36}$. Y es algo bastante parecido a lo expuesto por Peter Burke, quien considera tres variedades de la microhistoria:

1. La definición a medio camino que aquí se elige consiste en denominar «microhistoria” a cualquier análisis que se realice desde lo local o desde la pequeña escala para iluminar problemas más grandes [...] En palabras de Hans Medkk, consiste en ver la historia local como una historia general [...] como el análisis de una comunidad [...].

2. Una segunda variedad de la microhistoria podría denominarse "microbiografía", esto es, la biografía de un individuo relativamente insignificante [...].

3. Una tercera variedad de la microhistoria es la narrativa de un evento en pequeña escala que podría o no tener repercusiones más amplias [...1 Lo que ha sido denominado "el resurgimiento de la narrativa" también sustenta la microhistoria $[. . .]^{37}$.

Por consiguiente, la historia regional, la historia local y la microhistoria tienen una relación clara dada a partir de su delimitación en un espacio geográfico; no obstante, la historia local y la microhistoria dan cuenta de procesos políticos, económicos y culturales, entre otros, y ellas aportan a la construcción de la región histórica. Precisamente aquí está uno de sus complementos, como queda evidenciado en dos obras que logran amalgamar estas tres corrientes historiográficas: Montaillou, aldea occitana de 1294 a 1324, libro de Emmanuel Le Roy Ladurie $^{38}$ y Pueblo en vilo de Luis González ${ }^{39}$, en las que a partir de la comprensión de una localidad en un periodo determinado se llega al análisis de una región, no porque la historia regional se trate de una sumatoria de historia locales, sino porque historias locales pueden dar cuenta de fenómenos regionales. Este tipo de historiografías ayudan al historiador regional a conocer

35 Xenia von Tippelskirch, «La historia cultural en Alemania», en La historia cultural. ¿Un giro historiográfico mundial?, edit. Philippe Poirrier (Valencia: Universitat de Valencia, 2012), 226.

36 Miño Grijalva, «¿Existe la historia regional?», 867-897.

37 Peter Burke, «Toe invention of Micro-history», Rivista di Storia Economica: Nuova Serie XXIV (2008): 262.

38 Emmanuel Le Roy Ladurie, Montaillou, aldea occitana de 1294 a 1324 (Madrid: Taurus, 1981).

39 Luis González, Pueblo en vilo (Ciudad de México: Fondo de Cultura Económica, 1999). 
aspectos que en una visión macro no se vislumbran, y la historia regional ayuda a dar cuenta de las interrelaciones en el tiempo y en el espacio de fenómenos que la historia local y la microhistoria no pueden o no les interesa mostrar.

Por demás, la historia local se ha servido de la hermenéutica para recuperar las costumbres y la vida cotidiana de un grupo humano asentado en determinado lugar, pues a través de la constante interpretación de la información logra establecer relaciones entre los individuos que forman un colectivo, desentrañando las acciones, actividades y conductas, tanto individuales como colectivas, de las comunidades investigadas. Uno de los máximos exponentes de esta corriente es el mexicano Luis González, quien con su libro Pueblo en vilo elabora una narración a partir de archivos públicos y de personas locales sobre la historia de una localidad mexicana, y cómo esta pequeña localidad se articuló con procesos nacionales, rescatando así la importancia de visibilizar la acción de diversos actores sociales que quedan rezagados en la historia por pertenecer a localidades de diversa importancia.

De otra parte, a la microhistoria se le atribuye una constante pretensión por construir universos, fragmentos del acontecer de individuos o unidades a partir de fuentes procesales; sin embargo, estas representaciones del pasado solo son posibles de construir a través del análisis, la interpretación y el relacionamiento de la información particular con la intención de alcanzar el contexto general en que se desenvuelven los hechos históricos a interpretar. Un testimonio de este tipo de corriente historiográfica es el texto El queso y los gusanos de Carlo Ginzburg ${ }^{40}$, en el que el autor reconstruye las formas de pensar y vivir de un molinero en una provincia italiana a partir de los juicios inquisitoriales realizados en su contra por sus posturas cosmogónicas. Como lo menciona Tippelskirch, la microhistoria «abre un auténtico "giro hermenéutico" en la labor del historiador que implica la utilización de nuevas fuentes» ${ }^{41}$, las cuales no mostraban interés para los académicos, tales como periódicos, cartas, peticiones, sermones, actos jurídicos, actas de visitas pastorales y cualquier testimonio visual o material que permitiera conocer de primera mano la realidad de un personaje o pequeña comunidad.

Como se puede evidenciar hasta aquí, la historia regional, la historia local y la microhistoria son alternativas viables para rescatar la memoria de los pueblos, comunidades y regiones olvidadas; no obstante, es un trabajo complejo en el que debe existir interdisciplinariedad y diálogo con otras ciencias. Ahora bien, estas tres corrientes historiográficas se complementan en la diferencia. Por ejemplo, desde la microhistoria se puede complementar la historia regional o la historia local, pues en el caso de las obras señaladas de González, Le Roy Ladurie y Ginzburg, la fuente permite analizar todo un componente regional del grupo de personas que vivieron en un mismo lugar, lo cual implica reconocer y representar históricamente su cultura, su forma de vida, sus costumbres gastronómicas, sus festividades, sus creencias, sus enfermedades y pasatiempos, entre otras situaciones y actividades que señalan la cotidianidad de una comunidad. Giovanni Levi señala que «la microhistoria nació, al menos para mí,

40 Carlo Ginzburg, El queso y los gusanos: el cosmos de un molinero del siglo XVI (Barcelona: Muchnik Editores S.A., 1999).

41 Von Tippelskirch, «La historia cultural en Alemania», 226-227.

\section{Estudios históricos}


de la necesidad de reapropiarnos de una complejidad total en el análisis» ${ }^{42}$, es decir, lo que se podría considerar como una historia fragmentada a partir de interpretaciones aisladas es lo que lleva a comprender una historia total. Al realizar una microhistoria, fácilmente se podría tener un tipo de historia un poco más regional, pues ya no solo se conocería un personaje, sino que se tendría conocimiento acerca de quienes le rodearon en una misma localidad. El caso más relevante de este tránsito de microhistoria a historia regional se evidencia en la obra El queso y los gusanos, la cual, aunque se considera un clásico de la microhistoria, tiene un trasfondo de historia regional, pero con un fuerte componente de historia local. Esto ocurre porque la obra se basa en la historia judicial de un solo personaje (microhistoria), con una escala de análisis de una localidad (historia local), pero relacionada con la historia de un pueblo, lo que implica sus costumbres, geografía, creencias, demografía, etc. (historia regional). Muy similares son los casos de Pueblo en vilo y Montaillou, aldea occitana de 1294 a 1324, en donde sus autores a partir de fuentes orales, libros parroquiales y libros familiares permiten reconstruir la historia de un personaje, una localidad y una región y, a su vez, ligarle a una historia nacional, las cuales se han convertido en historias públicas universales, pues son textos de obligado estudio en los programas de Historia, especialmente en América Latina.

Las características mencionadas permiten determinar que es evidente una complementariedad entre la historia regional, la historia local y la microhistoria, pues al reconocerse en la necesidad de interpretar lo singular es posible, entonces, registrar la historia de un individuo o grupo humanos de cualquier lugar, bien sea una ciudad, región, municipio, Estado, pueblo o nación. Esta complementariedad refleja una identificación local a través de la vida cotidiana alrededor de la música popular, los cantos, las danzas, los mitos, creencias, costumbres, artesanías, usos y técnicas, vida cotidiana, mentalidades colectivas y demás aspectos de la cultura popular que se manifiestan en un tiempo y en un espacio determinados. Este conocimiento y su comprensión histórica están relacionados directamente con los estudios sobre los procesos económicos, sociales, políticos, culturales, institucionales e ideológicos, es decir, con la historia regional y con la historia general.

No obstante, en especial la microhistoria es un campo con las dificultades propias de cualquier corriente historiográfica. Pues el tiempo, el conocimiento, las perspectivas y la capacidad para comprender las relaciones complejas y cambiantes entre lo micro y lo global son algunas de las dificultades que deberá sortear el investigador interesado en estudiar una particularidad o una singularidad de un colectivo. Si en el caso de la historia general el espacio-tiempo largo es una categoría importante, en el caso de la microhistoria lo es el espacio-tiempo breve. De esta manera la microhistoria suele ser de espacio corto y tiempo largo, pero con un ritmo lento.

Pese a los puntos de encuentro existentes entre la microhistoria, la historia local y la historia regional, son tres corrientes historiográficas totalmente diferentes, es decir, complementarias, pero no equivalentes. Intentar una distinción entre estas tres corrientes historiográficas precisa una comparación crítica de las mismas. La mencionada complementariedad no significa equivalencia, pues la posibilidad de realizar en paralelo una investigación histo-

42 Giovanni Levi, Microhistorias (Bogotá: Universidad de Los Andes, 2019), 399. 
riográfica con estas corrientes es un potencial que depende de la capacidad del historiador y no es propiamente resultado de una necesidad metodológica o teórica.

\section{Conclusiones}

Uno de los mayores retos de los historiadores en la actualidad es considerar la historia regional, la historia local y la microhistoria como enfoques abiertos a la creación historiográfica, bajo el desarrollo de nuevas variables de análisis a partir de la construcción y selección de categorías, dado que en el panorama hay una multiplicidad de variantes y la mayoría de ellas están por construir y verificar. Igualmente, se hace necesario utilizar diversas unidades de análisis para tratar de abarcar a los grupos humanos en sus distintas dimensiones y relaciones.

La microhistoria, la historia local y la historia regional son tres tipos de historia diferentes, y cada una de estas tres formas de hacer historia ha producido un importante número de análisis en los que se mencionan sus características: la microhistoria es una historia que nace principalmente de la reflexión académica y profesional, y es entendida propiamente como un método, una forma particular de hacer historia sin renunciar a comprender procesos históricos más generales. Además, la microhistoria es entendida como la historia de una singularidad que ha tenido resultados exitosos cunado se elabora partiendo de procesos judiciales de situaciones específicas sorprendentes y no comunes. De otra parte, la historia local es posible entenderla como el estudio de una comunidad, de un singular colectivo, de tal manera que es una forma de hacer historia partiendo desde lo que acontece en una comunidad y puede tener relación con una historia más general. La historia regional se inscribe como el estudio histórico de un espacio geográfico en específico, incluyendo su población a la que se le analizan todos los ámbitos posibles como su geografía, su demografía, política, sociedad, economía y cultura, entre otros aspectos.

Por consiguiente, la historia local, la historia regional y la microhistoria se relacionan y son compatibles como formas de hacer historia, y aunque tienen diferentes enfoques y dificultades en su abordaje como realizaciones estrictamente científicas, sus recursos metodológicos hoy se reconocen como evidentemente invaluables para representar la historia acontecida de lo singular, lo particular dentro de una colectividad.

El reto para la historiografía es saber valerse de la historia local, la historia regional y la microhistoria para comprender el acontecer singular; también para profundizar en el estudio y análisis de nuevas particularidades en las cuales un actor o comunidad dejan ver mucho más variables para la comprensión del acontecer social, entre ellas incluso variables del orden psicológico. El propósito es también hacer historia, historia regional y microhistoria directamente relacionada con la historia general.

Un reto más amplio aún consiste en la necesidad de divulgar la historia, sea esta regional, local, micro o macro. Es evidente la falta de impacto de la Historia como asignatura en los jóvenes, quienes la toman como algo aburrido y sin trascendencia para su futuro. Si bien en

\section{Estudios históricos}


los últimos años se ha hecho el esfuerzo de divulgar la historia a través de museos, recorridos turísticos y la escritura de relatos, es cada vez más prioritaria la publicación de textos y la realización de diferentes actividades por fuera del ámbito académico, que registren una historia cercana al público; una historia un tanto más fresca sin perder su rigurosidad y en la que se reconozca el lector como miembro de una comunidad. Lo anterior sin olvidar que la historia pública debe propiciar nuevos espacios de interacción a través de la Internet. La aparición de blogs, animaciones, vídeos y un sinnúmero de herramientas digitales permitirán una mayor difusión de los acontecimientos históricos desde una visión actual, rigurosa en sus contenidos, pero más flexible en sus presentaciones a través de las redes sociales.

La academia está llamada a acercar la historia al público en general, a hacer públicos los acontecimientos que han formado una región, una localidad, una nación. Es probable que la historia se haya especializado en mostrar grandes batallas y en demostrar el impacto de los héroes nacionales en los procesos independentistas, o en los impactos de grandes personajes en la consolidación de la ciencia y la tecnología. Pero, sin duda alguna, el público también desea verse en la historia a través de los acontecimientos sucedidos en una localidad desconocida, en las situaciones vividas por un agricultor o comerciante; también anhela conocer la vida cotidiana de una familia en una época particular; argumentos que se pueden evidenciar en la historia regional, la historia local o en la microhistoria; para ello, la historia pública es fundamental y los historiadores estamos llamados a ser divulgadores de nuevas narrativas que estén al alcance de cualquier persona. Sin duda alguna, la tecnología, la fuente oral y el patrimonio material son mecanismos que ayudarán en esta labor, al igual que una interrelación entre diversas disciplinas tales como la arqueología, la sociología y la psicología, entre otras disciplinas.

La historia como ciencia, como saber disciplinario, debe acercarse al público, no debe estar escondida en anaqueles o archivos; por el contrario, debe estar disponible para todas las personas que quieran conocer la historia, porque «este enfoque centrado en el público, en la audiencia, es fundamental para comprender el trabajo de los historiadores públicos, y permite comprender realmente las posibilidades futuras para un trabajo transformador en ese campo» ${ }^{43}$. Y quizá la clave de estos nuevos trabajos historiográficos esté en la historia regional, la historia local y la microhistoria. Será labor de las nuevas generaciones de historiadores descubrir momentos, personajes y situaciones más allá de las gestas independentistas o de los actos fundacionales, que evoquen una historia cotidiana y amable, la cual, sin descuidar su análisis y cientificidad, se acerque a nuevos lectores en busca de experiencias narrativas diferentes.

\section{Referencias}

Acevedo Tarazona, Álvaro. «La historia regional: un campo abierto de problemas”. Revista de Ciencias Humanas UTP, 11, n. ${ }^{\circ} 45$ (2005): 99-108.

43 Anaclet Pons, «La Historia Digital y la "Historia Pública”», Clionauta: Blog de Historia, 25 de junio de 2020, acceso el 30 de diciembre de 2020, https://clionauta.wordpress.com/2010/06/25/la-historia-digital-y-la-historia-publica/. 
- "Avatares y tránsitos de la historia regional a la historia cultural: incertidumbres, extravíos y reencuentros». En Los historiadores colombianos y su oficio: reflexiones desde el taller de la historia, editado por Helwar Figueroa, José David Cortés Guerrero y Jorge Enrique Salcedo Martínez, 226-247. Bogotá: Pontificia Universidad Javeriana, 2017.

Aguirre Rojas, Carlos Antonio. «La historia regional en la perspectiva de la corriente francesa de los Annales». Revista Historia y Memoria n. ${ }^{\circ} 11$ (2015): 273-297.

Betancourt, Alexander. «El problema de la historia tradicional. A propósito de la reedición de dos obras clásicas de la historia local». En Identidades, localidades y regiones. Hacia una mirada micro e interdisciplinaria, compilado por Renzo Ramírez Bacca y Álvaro Acevedo Tarazona, 35-58. Medellín: La Carreta, 2007.

Burke, Peter. «Toe invention of Micro-history». Rivista di Storia Economica: Nuova Serie XxIV (2008): 262-264.

Carbonari, María Rosa. «De cómo explicar la región sin perderse en el intento. Repasando y repensando la historia regional». Historia Unísonos 13, n. ${ }^{\circ} 1$ (2009): 19-34.

Eddington, Arthur. Space, time and gravitation. Cambridge: Cambridge University Press, 1920.

Favaro, Orietta y María Carolina Scuri. Sujetos sociales y políticos. Historia reciente de la Norpatagonia Argentina. Buenos Aires: Clacso, 2005.

Ginzburg, Carlo. El queso y los gusanos: el cosmos de un molinero del siglo XVI. Barcelona: $\mathrm{Mu}-$ chnik Editores S.A., 1999.

González, Luis. Pueblo en vilo. Ciudad de México: Fondo de Cultura Económica, 1999.

González Rey, Diana. «Entrevista a Armando Martínez Garnica». Historia 2.0 IV, n. 8 (2014): 144-148.

Han, Byung-Chul. El aroma del tiempo. Un ensayo filosófico sobre el arte de demorarse. Barcelona: Herder, 2015.

Heidegger, Martin. Ser y tiempo. Santiago de Chile: Editorial Universitaria, 1998.

Lacomba, Juan Antonio. «La historia local y su importancia». En Actas I Congreso de Historia de Linares, coordinado por Vicente Leis Sánchez, Lorenzo Martínez Aguilar y Luis Rabaneda Sánchez, 455-470. Linares: Centro de Estudios Linarenses, 2008.

Le Roy Ladurie, Emmanuel. Montaillou, aldea occitana de 1294 a 1324. Madrid: Taurus, 1981.

Levi, Giovanni. Microhistorias. Bogotá: Universidad de Los Andes, 2019.

Martínez Botero, Sebastián. «La necesaria existencia de la historia regional o la tarea por construir la región». Gestión y Región n. ${ }^{\circ} 14$ (2012): 7-18.

\section{Estudios históricos}


Martínez Garnica, Armando. «Los conceptos de la historia regional santandereana». En Fronteras, regiones y ciudades en la historia de Colombia, coordinado por Amado Antonio Guerrero Rincón, 175-188. Bucaramanga: Universidad Industrial de Santander, 1993.

Martínez Garnica, Armando. «La historia local desde la perspectiva de la sociología de los regímenes». En Historia local. Experiencias, métodos y enfoques, compilado por Renzo Ramírez Bacca, 29-60. Medellín: La Carreta, 2005.

Miño Grijalva, Manuel. «¿Existe la historia regional?». Historia Mexicana LI, n. 4 (2002): 867-897.

Poirrier, Phillippe, ed. La historia cultural: ¿Un giro historiográfico mundial? Valencia: Universitat de Valencia, 2012.

Pons, Anaclet. «La Historia Digital y la "Historia Pública”». Clionauta: Blog de Historia, 25 de junio de 2020. Acceso el 30 de diciembre de 2020. https://clionauta.wordpress. com/2010/06/25/la-historia-digital-y-la-historia-publica/.

Ramírez Bacca, Renzo y Álvaro Acevedo Tarazona. Identidades, localidades y regiones. Hacia una mirada micro e interdisciplinaria. Medellín: La Carreta Histórica, 2007.

- «Tendencias de la historia regional en Colombia. Problemas y perspectivas recientes». Historelo. Revista de Historia Regional y Local 3, n. ${ }^{\circ} 5$ (2011): 147-168.

Torres Ayala, Daniela. «Historia pública. Una apuesta para pensar y repensar el quehacer histórico». Revista Historia y Sociedad n. ${ }^{\circ} 38$ (2020): 229-249.

Vizcaíno González, Lilian. «La historia regional. Mitos y realidades”. Tzintzun: Revista de Estudios Históricos n. ${ }^{\circ} 27$ (1998): 116-129.

Von Tippelskirch, Xenia. «La historia cultural en Alemania». En La historia cultural. ¿Un giro historiográfico mundial?, editado por Philippe Poirrier, 217-232. Valencia: Universitat de Valencia, 2012.

Zuluaga Ramírez, Francisco Uriel. «Oteando el horizonte de la historia local». En Historia local. Experiencias, métodos y enfoques, compilado por Renzo Ramírez Bacca, 113-134. Medellín: La Carreta, 2005.

. «Otro paso en la reflexión sobre historia local». Historelo. Revista de Historia Regional y Local 1, n. ${ }^{\circ} 2$ (2009): 169-181.

- «Historia local y hermenéutica». Historelo. Revista de Historia Regional y Local, 2, n. ${ }^{\circ}$ 3 (2010): 143-155. 